\title{
Preventing Drug Abuse among Children and Adolescents: Where Does the Salutogenic Approach Direct Us?
}

\author{
Shifra Sagy \\ Department of Education, Ben Gurion University of the Negev, Beersheva, Israel \\ Email: shifra@bgu.ac.il \\ Received 8 December 2013; revised 14 January 2014; accepted 22 January 2014 \\ Copyright (C) 2014 by author and Scientific Research Publishing Inc. \\ This work is licensed under the Creative Commons Attribution International License (CC BY). \\ http://creativecommons.org/licenses/by/4.0/ \\ c) (i) Open Access
}

\begin{abstract}
The "science of prevention" approach has advanced research in the realm of drug abuse. Emphasis, however, was clearly accorded to risk factors rather than to uncovering protective factors. In the 1980s, Antonovsky proposed a new paradigm-salutogenesis-which provided a different theoretical and practical basis for constructing and evaluating prevention programs. According to the salutogenic model, prevention programs should relate to the extent that these protective factors advance youths-as well as the systems in which they live-towards promoting comprehensibility, manageability, and meaningfulness. The paper describes salutogenic directed programs and research, and discusses the contribution of the theory to advancement of both practice and research in the area of drug abuse.
\end{abstract}

Keywords

Drug Abuse; Adolescents; Salutogenesis; Prevention

\section{Introduction}

The concept of primary prevention, as it is accepted today in the realm of public health and emotional health, first appeared in the 1960s [1] [2] and constituted a dramatically different step in research and practical discourse regarding sickness and health. This approach suited the American political atmosphere of those times and only a few raised their voices against it (see, for example, [3]). However, this concept remained on the margins of discourse for a long period, while treating the disease after it had appeared ("tertiary prevention" according to Kaplan) continued to be central, both in physical and in emotional health [3] [4]. This development involved implications, of course, for education and for its implementations. 
Only in the 1990s did "primary prevention" [1] gain renewed attention, and was even proposed as a new interdisciplinary research area (prevention science) in the contexts of psychopathology, criminology, psychiatric epidemiology, child development and education. In 1993, the important psychology journal, American Psychologist, published an article by a group of researchers who discussed the subject. The discussion took place with the support of the National Institute of Mental Health (NIMH) of the United States and the article, entitled “The science of prevention: A conceptual framework and some directions for a national research program” [5] was published. This article constituted a breakthrough in the psychological thinking which had been accepted until then, particularly in the United States, which then began to emphasize prevention as an important realm of research. The aim of the science of prevention was defined as "to prevent or to moderate human dysfunction" (Ibid., p. 1013).

One of the important goals of the science of prevention, as defined in that article, was research into the causes of illness or dysfunction, that is, the risks and protective factors. In this fundamental research, the authors examined the basis of the relationship between science and practice in preventive interventions. On the other hand, the authors added experiments in the field of interventions which could supply ideas about the causes of dysfunction and developmental processes which lead to illness or to health. Acceptance of this approach as an appropriate and meaningful research field in psychology and in education has greatly advanced research in the realm of prevention of drug abuse and especially in evaluation studies of interventions in this field.

However, even when prevention had been accepted as an appropriate research field for attention (and that really was an important revolution), emphasis was clearly accorded to risk factors rather than to uncovering protective factors. In that article from 1993, only a short section (one out of 10 sections) referred to advancing knowledge of protective factors, such as, for example, psychological resilience, skills and environmental benefits. Even in this section, emphasis was placed on research among groups at risk, in order to identify and to describe protective factors and those which aid in coping, despite the risks. Research on protective factors/resilience factors among the general population are not mentioned at all in this article. Thus, even when a change in direction did take place, and when the approach was directed at preventive research in physical and mental health, the fundamental point of departure was pathogenic.

The pathogenic approach — which is still very commonly accepted today in Western medical and psychological thinking-perceives of the human system as being attacked by a pathogen, any factor (a microbe or any other danger) which causes harm; a chronic or acute illness. The bio-social-psychological approach is also based on this assumption, but it broadens the pathogenic factors beyond biological factors to include social and psychological factors. In other words, if we only prevent the pathogenic factor from harming us, we will be fine. The basis of all pathogenic approaches is the dichotomous division between those who have been harmed by a pathogenic factor and as a result have become ill (physically or emotionally) and all the rest of us who have remained unharmed. Put differently, the basis of the approach is that people are meant to be healthy. All they have to do is to avoid risks or pathogenic factors. Even those researchers, who attempted to advance prevention concepts or to promote health, primarily based their ideas on this dichotomous division [6]. If we accept this direction on a social and educational level, what we must do as a society is to reduce or eliminate the risk factors in order to prevent disease or dysfunction. As researchers, we must clarify what these factors are; as educators, we must eliminate them from the lives of our children and our adolescents in order for them to stay healthy.

At the end of the 1980s, Aaron Antonovsky proposed a new paradigm for thinking about illness and health, and thus, also about prevention, as well as about the promotion of health. He proposed the salutogenic theory as directed towards both theory and practice, in place of the pathogenic theory [7]. The fundamental philosophical assumption of the salutogenic theory is what makes the difference in direction of the two different approaches. Instead of perceiving of the human system as a sound one, except when it is attacked by some kind of pathogen, the salutogenic approach sees the human system as basically unsound, and constantly being attacked by disruptive processes and factors which cannot be prevented (including the ultimate end of this system, death).

The salutogenic approach assumes that every person lives in a world of stimuli which arouse constant and unavoidable stress. Reading the newspaper in the morning, watching the news in the evening, the environmental pollution which threatens us - all of these constitute a state of continual stress for every person. Young people live in a state of ceaseless stress in the modern (or postmodern) world, or so it appears. If this is how we perceive life in the universe, we develop different ideas and especially, different questions in the realm of prevention, health and the promotion of health. Instead of asking and researching what the risk factors are, we assume that, in any case, these factors surround us throughout our lives, and usually, we cannot prevent them. Therefore, the 
question is: Despite this continual state of risk and threat around us, how is it that most people are not physically or emotionally ill (for example, most young people are not addicted to drugs). Salutogenesis suggests changing the dichotomous answer of health versus illness to thinking in terms of the model of a continuum between ease and disease. It proposes to replace the question of risk factors with the question of the extent to which we know how to deal with the difficult world around us.

Where does the salutogenic question direct us in terms of prevention?

As the basic assumptions of those who promote prevention and the advance of health are in fact pathogenic, the science of prevention is mostly involved with those who are at risk and deals with the risk factors, the pathogens. The result of concentration on pathogens is expressed in the planning of most of the programs to advance prevention: a reduction in the risk factors. In order to answer the question of prevention salutogenically, we must focus less on risk factors and ask more about the factors which advance us in the direction of health on the continuum of ease-disease, upon which we exist in any case. The salutogenic direction in prevention, then, means that we do not investigate the risk factors and eliminate them, but rather examine those factors which actively enable the individual to maintain his/her health or to advance it. Those are the factors that protect us (as described by Coie et al. [5]) or in terms of the salutogenic model, the salutogenic factors [7].

Thus, the salutogenic approach encourages us:

1) To investigate the entire population (and not just groups who are at risk) as being somewhere on the continuum of ease-disease.

2) Instead of searching for the causes of illness or dysfunction, to focus on the factors which promote health and to ask about them.

3) The answers to the salutogenic questions can be many and varied: sociological factors, genetic factors, developmental or emotional factors. The scientific literature which has developed in recent decades regarding resilient children who have succeeded in surviving and functioning well in environments at risk (like families, schools, or distressed neighborhoods) have supplied increasing evidence of significant resilience factors which could serve as a basis for prevention programs [8]-[11].

Antonovsky's answer to the salutogenic question was an all-encompassing one and referred to the individual cognitive concept-which includes cognitive, emotional and behavioral components-the sense of coherence. He reached this concept while searching for a common factor which would connect the various resources appearing in the literature as contributing factors to good coping and to promoting health (social support, belief, money, among others). The model developed by Antonovsky suggested that the factor common to all of these resources was that they supplied life experiences which together would construct a worldview. He defined this worldview as the sense of coherence [7]. Thus, sense of coherence is a concept which describes an outlook, a cognitive orientation, expressing the tendency to see the world as a logical and reasonable place, not chaotic, which may be managed both emotionally and instrumentally.

The three components of the sense of coherence are comprehensibility, manageability and meaningfulness. Comprehensibility refers to the cognitive tendency to find order in the world, which facilitates understanding of the stimuli and the problems caused by the state of stress. Manageability refers to the tendency to expect that it is possible to cope with the demands posed by the stress factors with the resources available to the individual or to the people on which she/he depends. Meaningfulness refers to the tendency to see life as being meaningful. This meaning is what supplies the individual with the will and the motivation to deal with the stress, and the tendency to see the demands of the stress factors as challenges worthy of the effort and investment which must be made to cope with them.

\section{Discussion}

If we accept the salutogenic approach, we must change our basic approach to the concept of prevention and its derivations. The science of prevention as it is defined by Coie and his colleagues [5] includes research which principally is meant to prevent, to negate or to moderate something, usually, an illness or an undesirable behavior and its causes. Such an approach often presents a certain object against which a prevention program is directed and as a result, it highlights the negative messages in the context of that very object.

When proceeding from the salutogenic model, the approach to prevention has a fundamentally different meaning. The salutogenic doctrine dictates that we must relate to prevention programs with an approach which emphasizes the positive and holistic goals that the program is meant to achieve. This means that instead of ask- 
ing about the risk factors and trying to prevent them, we will ask about the salutogenic factors which contribute to the enhancement of a sense of coherence (in the individual and in the community), and to try to develop them.

It is important to stress that the sense of coherence is actually a rich and measurable concept which has been supported by many studies all over the world as a significant factor in the advancement of health and welfare (for a comprehensive review, see [12]). However, it is as well possible to "adopt" other salutogenic concepts in accord with the outlook of initiators and operators of such programs.

The preventive approach which stems from the salutogenic model leads us to emphasize elements which strengthen salutogenic factors (cognitive, emotional and behavioral) among young people:

1) Acquiring the skills to view the world as being understandable;

2) Broadening personal and social resources which are available to the young person;

3) Clarifying the meaning of life and the challenge in coping with the world.

Above and beyond intensifying the individual's sense of coherence, it is important to widen the scope of intervention on the ecological-systemic level in which the young people are growing up. On this level, instead of directing and operating programs for special groups at risk-we focus on the general population. The practical significance is the advancement of the community (schools, neighborhoods and others) in order to strengthen the sense of comprehensibility, manageability and meaningfulness among its members. Research evaluation of salutogenic programs such as these will be directed especially towards investigating a rise in the sense of coherence among its participants, both as individuals and as a system.

In recent years, we have been witness to an additional development in the study of resilience, which directs us towards integration between two approaches and a focus on the study of the mutual relations between risk and protective-salutogenic factors [13]. Such an integrated approach should contribute both to the advance of the salutogenic and holistic orientation without abandoning the study of the emotional, social and environmental factors with regard to the specific issue of prevention of drug abuse.

What has been done until now?

A research survey has indicated a number of factors (e.g., decision-making, self-esteem, self efficacy) which advance resilience, especially among young people who have been defined as youth at risk. Research literature has found that some of the protective factors actually reflect coping skills, life skills which are acquired by "resilient" children while interacting with their environment. These factors have begun to constitute a basis for prevention programs. Thus, in the realm of prevention of drug abuse in recent decades, some of the programs have resulted from multi-component models directed towards building and strengthening psycho-social factors, by building skills and strengthening the sense of personal ability [13]-[16]. But even with those advances, positive and creative programs have usually placed the emphasis on risk factors, leaving us in the content area of prevention of dysfunction (or illnesses) and have been satisfied with proposals for a healthy lifestyle, at best.

However, in evaluation studies relating to the effectiveness of these programs it became clear that they did not only contribute to a change in attitudes towards drug abuse, but also affected personal variables such as locus of control, self image, need for acceptance and others [17]. For example, in evaluation research of the DARE program (Drug Abuse Resistance Education), which was extensively used in schools in the US in the 1990s, positive effects of the program were observed in general, even though the emphasis was still on the drug problem [1]. Evaluation research of other programs has been principally based on their ability to prevent drug abuse and to increase resistance to drug use [16] [18].

Few studies only have evaluated the effects of these programs on wide-ranging salutogenic factors (of the individual and the school system) through time and in comparison to control groups. Such an investigation could enrich our broad knowledge about the relationship between salutogenic development and specific risk factors.

One such study [19], which included the specific question of a change in attitudes towards drugs, found, for example, that despite the fact that there was no dramatic change in attitudes towards drugs after the intervention program, there was a change in the relationship between the attitudes of the adolescents and their sense of coherence. In other words, after the program, the relationship between their attitudes and their sense of personal coherence was strengthened in comparison to the devaluation which took place in the relationship between the adolescents' attitudes and their perception of their friends' attitudes. The significance of this finding is that, after the program had been implemented, attitudes towards drugs were more affected by the personal worldview of the adolescents and less by the attitudes of their friends. It appears that these results direct us towards understanding the importance of the broad and holistic salutogenic factor even in advancing the more specific subject of preventing drug use. 
What is a prevention program which is salutogenically directed?

In recent decades, a small number of holistic programs have been developed all over the world which are salutogenically directed. The program "Life Skills", for example, operated under the auspices of the Psychological Counseling Service in Israel from the 1990s, provides a good example of an attempt at a salutogenically directed program. This comprehensive long-term developmental program is directed towards the entire population and not only towards groups at risk. In fact, it does include aspects of prevention, but it goes beyond these aspects [20]. The program is eclectic and flexible and it is constructed by panel discussion within the educational system. However, in addition, and perhaps due to its varied eclecticism, the program lacks a structured theoretical basis which is clear, meaningful and lucid. Such a basis could supply the understandable and comprehensive theory as proposed by Antonovsky. The theory is important both for constructing a program and for implementing it. Accordingly, when evaluating such a program in research, salutogenic questions should be asked: To what extent does the intervention program advance the youths and the systems in which they live (the classroom, the school, the neighborhood and others) in three salient directions_comprehensibility, manageability and meaningfulness?

What is salutogenically directed research?

In order to answer this question, I will describe an example of salutogenically directed research, theoretically based and directed towards implementation [21]. The research aimed to identify and to measure coping resources in the context of the community, as they were experienced by the youth of three communities in small southern Israeli cities. The samples included 1000 high school students from the eighth to the eleventh grades of six schools in these cities.

The model at the basis of this study integrates salutogenic theory and knowledge which has been accumulated from the research literature with regard to resilience and resources on a community level. The novelty of the work is the construction of a unique tool to investigate sense of coherence on a community level, as it is perceived by youth who are growing up and living in the community. The basic research hypothesis is that a salutogenic community can constitute a source for the development of personal coping resources in the youth who have been growing up there, to deal with pressure, and, in addition, to prevent specific risk behaviors (such as use of psychoactive substances). We investigated the community resources in terms of their contribution to the three components of the Sense of Community Coherence:

A. Community resources for comprehensibility-The community was investigated as a source of resources which promote the sense that the place where the youths live is a safe and secure place where life can be anticipated. This component was measured by the perception among the youth that the community and its organizational systems are comprehensible and well known. The items investigated the extent to which the community is perceived as safe and foreseeable for the young people, the extent to which the adult residents are perceived as being aware of and understanding the needs of the youth, and the extent to which the young people see the community in their future. The tool was based on a questionnaire asking about the sense of school coherence [12] and was suited to the community framework. Examples of the items include:

"Young people who live in this city can feel safe."

"I see my future in this city"

B. Community resources for manageability-This component investigated the community as a source of resources which assist the youth in coping with distress and crises which are characteristic of adolescence. The resources which advance community manageability were defined by professionals and programs which the youth can turn to in times of crisis and adversity. For example: people who may provide psychological treatment to the youth, programs for youth groups under the auspices of the Welfare Department, programs to prevent school drop-out. In the questionnaire, statements about services available to young people in the community for coping with difficulties and crises were examined. Examples included:

"If one of my friends has a personal problem, there are professionals in the city who can help him/her."

"I am acquainted with the services and organizations in the city which can help me to overcome my problems and difficulties."

C. Community resources for meaningfulness-Our question in this component is the extent to which the community is perceived as a source of possible resources for young people to express and to realize themselves, to feel satisfaction, interest and challenge. Examples of these items are:

"The city is a source of pride to its residents."

"The community centers in this city supply young people with interesting possibilities for entertainment in their free time." 
"Every week I find myself waiting for an activity which I have registered for."

The youth were requested to mark the answer which reflected their measure of agreement with each of the items on a Likert scale ( 5 = very much agree, $4=$ agree, $3=$ not sure, $2=$ do not agree, $1=$ reject). The new tool to investigate community sense of coherence which was constructed for this research was found to have a high reliability (Cronbach’s Alpha of 0.93).

As described above, using this research tool, the study investigated the effect of community on the development and personal growth of young people. The findings of the research actually did testify to the fact that the specific community characteristics on which the research focused, constituted resilience factors of community resources which enable personal development and the expansion of coping ability among youth growing up in that community (as evaluated by other measures) [21]. This is a meaningful answer to the salutogenic question in the community context. Moreover, significant differences were found between the three examined communities in the level of the impact the community resources had on the personal sense of coherence of young people. In the town in which the community sense of coherence was highest, the level of relationship between the sense of community and the sense of personal coherence was stronger than in the other two cities.

Back to our theme in this paper, this community study also asked about the prevention of drug abuse. The findings indicated that sense of community coherence explained $8 \%$ - 17\% of orientation towards drug abuse, actual use of psychoactive substances, and exposure to drugs among the adolescents. In other words, the findings show not only the holistic development of adolescents in those cities, in which community sense of coherence was found to be high, but also the relationship between characteristics of salutogenic community resilience and a decline in the percentages of a specific risk behavior connected to drugs among the adolescents. These findings are in accord with some other studies which have focused on the relationship between community resilience factors and involvement of adolescents with undesirable or illegal behaviors [22] [23].

An additional significant point raised by the findings relates to risk factors in the family. In accord with the salutogenic approach, the research referred to the general population of adolescents in the communities which were examined. However, when the research hypotheses were examined among pupils from a low socioeconomic background, the relations between sense of community coherence and risk behaviors (use of psychoactive substances) were found to be stronger than in the general sample. In other words, among the students exposed to a low socioeconomic level, the positive effect of community coherence was even higher than in the general population of students. These findings can teach us about the interaction between risk factors whose source is in the family and the importance of salutogenic resilience factors of the community. The findings are in accord with other studies (see for example [24] which have focused on children from troubled families who participated in extracurricular educational programs initiated by the community. The activities were found to have significantly contributed to these children (in comparison with the general population of students) completing of their high school studies. It appears that the community had a powerful and salutogenic effect on the totality of adolescent members, but a special effect actually could be found among youth in distress.

In summary, the community research which I have described employed the salutogenic approach and asked about the components of a salutogenic community and its effect on the development of adolescents. Moreover, the research integrated an investigation of risk factors towards a specific behavior. It appears that this integration contributes to the possibilities of application of the research conclusions in community work.

\section{Conclusion}

Finally, interest in salutogenesis is not new, but appears to be presently developing momentum and thus, a clearer theoretical framework is needed. Programs directed towards prevention of drug abuse have also increased in recent years and they include multi-component models of various resilience factors. The salutogenic model emphasizes the importance of directing programs to the general population and not just to groups at risk for specific behaviors. Nevertheless, weaker population groups — as we have seen in a variety of studies — can benefit from community programs even more. Regarding prevention on the system level, there is no doubt that short-term school prevention programs cannot achieve salutogenic results. In order for children to learn in a salutogenic system — which promotes comprehensibility, manageability and meaningfulness—a continuous educational process is needed, one which is organic and structured. For that to happen, we must, first of all, focus on constructing a basic infrastructure of salutogenic advancement in the communities and in the educational systems within them. How can we do this? Only with cooperative thinking directed towards salutogenesis, for all 
members of the communities which compose our school system—departments of education, principals, teachers, parents and children.

\section{References}

[1] Caplan, G. (1964) Principles of Preventive Psychiatry. Basic Books, New York.

[2] Sarason, S.B., Levine, M., Goldenberg, I., Cherlin, D.L. and Bennett, E.M. (1966) Psychology in Community Settings. Wiley, New York.

[3] Albee, G.W. (1998) Fifty Years of Clinical Psychology: Selling Our Soul to the Devil. Applied Preventive Psychology, 7, 189-194. http://dx.doi.org/10.1016/S0962-1849(05)80021-6

[4] Bowen, G.L., Richman, J.M., Brewster, A. and Bowen, N. (1998) Sense of School Coherence, Perceptions of Danger at School, and Teacher Support among Young at Risk of School Failure. Child and Adolescent Social Work Journal, 15, 273-286. http://dx.doi.org/10.1023/A:1025159811181

[5] Coie, J.D., Watt, N.F., Stephen, G.W., Hawakins, D., Asarnow, J.R. Markman, H.J., Ramey, S.L., Shure, M.B. and Long B. (1993) The Science of Prevention: Conceptual Framework and Some Directions for a National Research Program. American Psychologist, 48, 1013-1022. http://dx.doi.org/10.1037/0003-066X.48.10.1013

[6] Antonovsky, A. (1996) The Salutogenic Model as a Theory to Guide Health Promotion. Health Promotion International, 11, 246-253. http://dx.doi.org/10.1093/heapro/11.1.11

[7] Antonovsky, A. (1987) Unraveling the Mystery of Health: How People Manage Stress and Stay Well. Jossey-Bass, San Francisco.

[8] Cowen, E.L. and Work, W.C. (1988) Resilient Children, Psychological Wellness and Primary Prevention. American Journal of Community Psychology, 25, 141-157.

[9] Kumpfer, K.L. (1994) Resiliency and AOD Use Prevention in High-Risk Youth. In: Kumpfer, K., Ed., Building Resiliency to Alcohol and Other Drug Use, Kluwer Academic Plenum Publishers, New York.

[10] Peterson, A.C., Sarigiani, P., Leffert, N. and Camarena, P. (1998) Resilience in Adolescence. In: Scwartzberg, A.Z., Ed., The Adolescent in Turmol, Prager, Westport.

[11] Wolff, S. (1998) The Concept of Resilience. Australian and New Zealand Journal of Psychology, 29, 565-574. http://dx.doi.org/10.3109/00048679509064968

[12] Ericksson, M. and Lindstrom, B. (2006) Antonovsky’s Sense of Coherence Scale and the Relation with Health-A Systematic Review. Journal of Epidimiology and Community Health, 60, 376-381. http://dx.doi.org/10.1136/jech.2005.041616

[13] Rosman, M. and Aviad, Y. (1990) Drugs in Your Head: A Program for the Prevention of Abuse among Adolescents. University of Tel Aviv, Ramot.

[14] Lahav, Y. (1989) Amana: Unity of Educators, Youth and Parents. T.L.M. The Kibbutz Center for Child and Family Therapy.

[15] Leket, R. and Leipzinger, E. (2004) Evaluation of a Program of Drug Use Prevention. Psychological Counseling Service, Ministry of Education.

[16] Feingold, V. (1996) Evaluation of an Educational Program for the Prevention of Drug Abuse. Thesis, Ben Gurion University of the Negev.

[17] Hansen, W.B. (1992) School Based Substance Abuse Prevention: A Review of the State if the Art in Curriculum, 1980 - 1990. Health Education Research: Theory \& Practice, 7, 403-430. http://dx.doi.org/10.1093/her/7.3.403

[18] Navon, D. and Liberman, G. (1992) Evaluation of Programs for the Prevention of Drug Abuse and Alcohol Drinking. The Department of Youth Advancement, Tel Aviv Municipality.

[19] Sagy, S., Komay, V. and Feingold, V. (1995) Prevention of Drug Abuse among Adolescents: Evaluation of Prevention Programs in Schools. Lecture at the $25^{\text {th }}$ Scientific Convention of the Association of Psychologists in Israel, Beersheva.

[20] Shadmi, C. (2004) The School Counselor and Promotion of the Optimum. In: Ehrhard, R. and Klingman, A., Eds., School Counseling in a Changing Society, University of Tel Aviv, Ramot.

[21] Alfasy, Y. (2012) What Is a Salutogenic Community? Youth Perceptions of Their Community Characteristics as Related to Development of Their Tendency to Avoid Risk Behavior. Unpublished Dissertation, Ben Gurion University of the Negev.

[22] Jessor, R., Tunlin, M.S. and Costa, F.M. (1998) Risk and Protection in Successful Outcomes among Disadvantaged Adolescents. Applied Developmental Science, 2, 194-208. http://dx.doi.org/10.1207/s1532480xads0204 3

[23] Fagan, A.A., Van Horn, M.L., Hawkins J.D. and Arthur, M. (2007) Using Community and Family Risk and Protective 
Factors for Community Based Prevention Planning. Journal of Community Psychology, 35, 535-555. http://dx.doi.org/10.1002/jcop.20163

[24] Gilman, R., Meyers, J. and Perez, L. (2004) Structured Extracurricular Activities among Adolescents: Findings and Implications for School Psychologists. Psychology in Schools, 41, 31-41. http://dx.doi.org/10.1002/pits.10136 